\title{
Jane Buyers
}

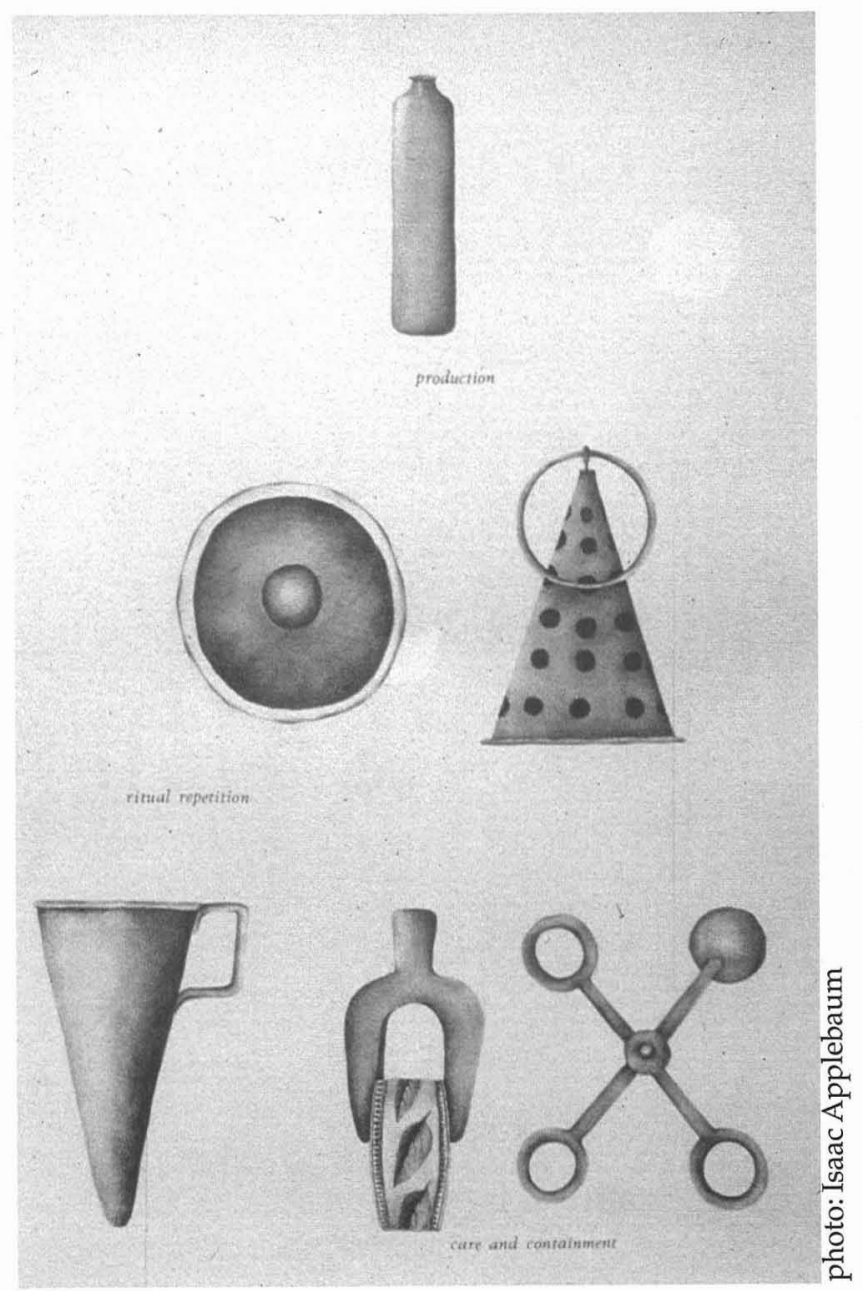

Care and Containment, 1990

graphite, text,

$67.5 \times 51 \mathrm{~cm}$ 


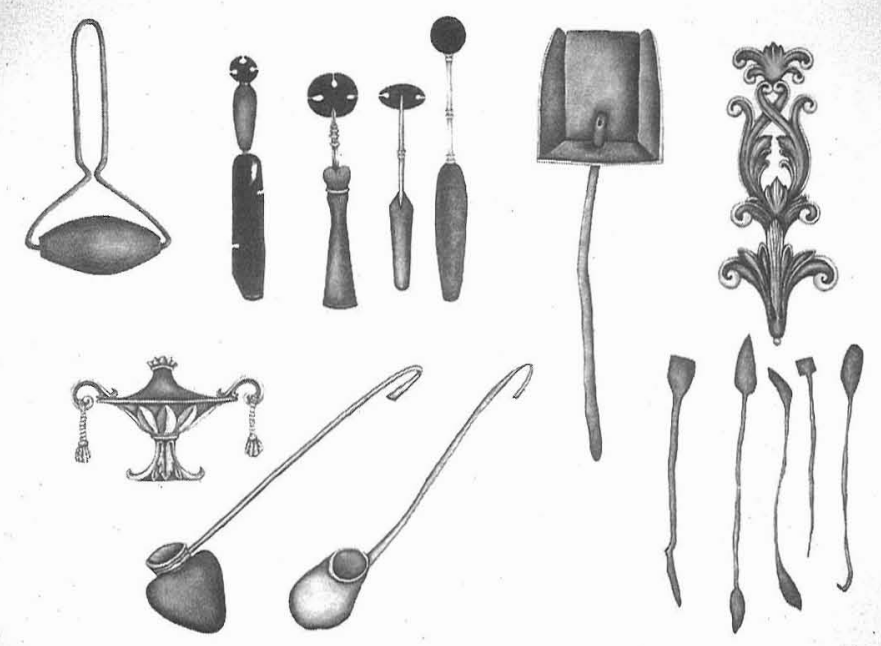

History Lesson \#3: The Order of Things

1993, graphite, $79 \times 108 \mathrm{~cm}$

Collection of Woodstock Gallery

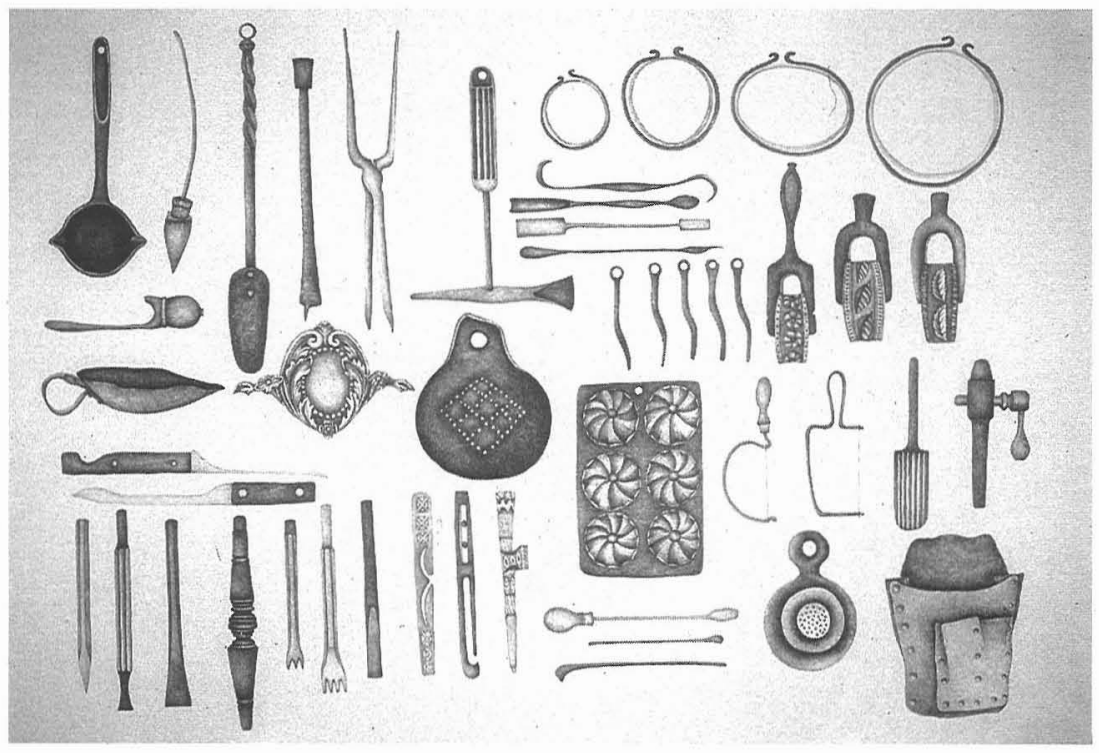

History Lesson \#8: The Order of Things

1994 , graphite, $83.5 \times 115.5 \mathrm{~cm}$ 

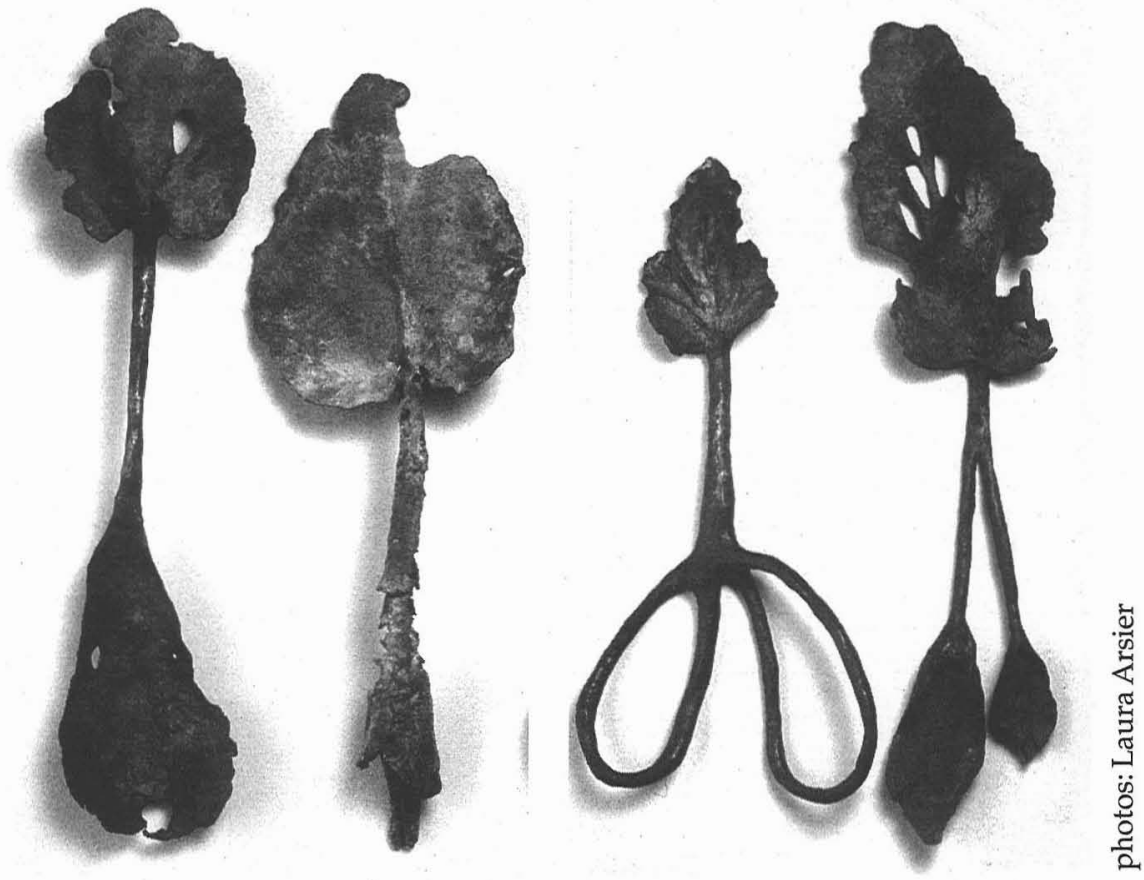

Pratica\#3

1995 , two of seven parts, bronze

$40 \mathrm{~cm}$ length 